piece of pork $\frac{1}{2} \times \frac{3}{8}$ inch. There were cavities in the lower lobe. There was acute pneumonia at the lower part of the upper lobe with cedema of the left lung. Had the pork been there for six months?

CASE 20. Pieoe of wood in left bronohus; bronohieotasis of both lungs.- In 1905 a female child, aged 16 months, was admitted. She was well until five weeks before admittance, when she had a cough and dyspnca. The right lung was resonant on the anterior part in front, but impaired behind. There were crackling râles, bronchial breathing, and pectoriloquy behind.

At the inspection there was advanced fibrosis with bronchiectasis of the right lower, the right middle, and the left lower portions, with a mass of dilated tubes in the midst of the parts of the lung which were fibroid. The trio left upper lobes were distended; there was recent bronchopneumonia. In the left bronchus just beyond the point of bifurcation there was a smooth piece of wood broken off a toy. It was doubted at the necropsy whether the piece of wood had caused the bronchiectasis, because it was found in the left bronckus and the bronchiectasis was also on the right side, but probably at an earlier stage it was in the right bronchus, and had produced changes on that side and been displaced to the left later.

Although many cases of foreign bodies in the bronchi have been recorded, in but very few has an accurate note been made of the physical signs in the lung in an early stage of the illness. The body generally passes into the right bronchus because it is more vertical and is also slightly larger. The changes are unilateral, serious, and progressive. The following are the most important evidences suggestive of a foreign body in a bronchus, and in any such case a bronchoscope should be passed in order that the condition of the tubes may be determined, and a positive opinion formed. 1. A most important factor in diagnosis, and one which until we had $\mathbf{X}$ rays was absolutely essential, is the history of swallowing something immediately before the onset of an acute attack of severe dyspncea and cough. 2. Not infrequently a whistling or wheezing sound which the patient can localise to one side, varying in quality if the object is not fixed in the bronchus. 3. Great distress, with not infrequently a constricting pain behind the sternum, made worse by movement. 4. Dyspnoea, with varying exacerbations, often intense and made worse by cough, but it may be elicited only by exertion. After a time there may be no distress. 5. Absent or, rarely, very noisy breath sounds with some slight diminution of voice and tactile vocal fremitus limited to one side of the chest. 6. At first resonance on the affected side, soon consolidation with dulness, and, after a time, the signs of cavities and the simulation of phthisis; query occasionally hyper-resonance. The physical signs sometimes vary from time to time. 7. With $\mathrm{X}$ rays, the defective movement of the diaphragm and of the thorax, the alteration in the density of the lung, and not infrequently the outline of the foreign body itself, may be clearly made out. 8. Delay in the commencement of inspiration as compared with that on the other side. 9. Defective movement with consequent diminution in the size of the affected side. 10. Violent paroxysmal persistent cough, which is apparently most marked when the object is at the bifurcation, as the sensibility of the mucous membrane is greatest here, as can be noticed when passing a bronchoscope. 11. Early pyrexia, which later becomes hectic, associated with chills. 12. After a short time an expectoration more or less profuse, purulent, often bloody, and later often fotid. 13. In some there are nausea and vomiting which may be very troublesome. 14. Pneumonia often develops in 48 hours; this may be septic and may be followed by gangrene.

Royat Collegg of Physicians of London.-An Extraordinary Comitia was held on Dec. 1st, Sir Thomas Barlow, Bart., K.C.V.O., the President, being in the chair. The President announced that Sir James Sawyer had presented to the College a reproduction of the arms of Harvey. In order to procure the needful information a prolonged research had been necessary, and the thanks of the College were heartily returned to Sir James Sawyer for the gift. A communication was received from the secretary of the Royal College of Surgeons of England, dated Nov. 4th, 1910. The remainder of the proceedings were declared by the President to be secreta Collegii.

\section{THE THEORY AND PRACTICE OF THE TREATMENT OF SYPHILIS WITH EHRLICH'S NEW SPECIFIC "606."}

\author{
BY JAMES MCINTOSH,
}

GROCERS' RESEARCH SCHOLAR ; AND

PAUL FILDES.

THE demonstration by Hata of the lethal effects of " 606 " on spirochrtes in the case of certain experimental spiro. chætoses led one of us (J. McI.) ${ }^{2}$ to experiment later with it on the Spirochrta obermeieri of relapsing fever. The signal success of these experiments without injury to the animals induced us to follow the example of several eminent continental syphilologists and apply the remedy to syphilis. For this purpose, by the great generosity of Geheimrat Ehrlich, Dr. Bulloch was able to obtain a further supply of "606." We are therefore much indebted to Dr. W. Bulloch. for entrusting to us its practical application.

The descriptions of the results of Ehrlich's new arsenical preparation dioxydiamidoarsenobenzol ("606") as a specific cure for syphilis and other diseases due to spirochætæ have been couched in language of admiration, which is unusual in medical literature. Alt, A. Neisser, Schreiber and Hoppe, Iversen, Pick, Duhot, Finger, Wechselmann, Michaelis, and others have all written in praise of this substance as a cure. for primary, secondary, tertiary $y_{7}$ and congenital syphilis A. Neisser asserted that " 606 " was far superior to mercury or any other arsenical compound, while Uhlenhuth has discarded his efficacious mercuric atoxyl in its favour. Several of the above authors have recorded cases in which pro. longed mercurial treatment had been followed without success, only to heal rapidly under "606." Such cases can be observed by anyone who has had the opportunity of asing this substance. Its remarkable effects are obvious, but, nevertheless, we are of opinion that some recent authors have unduly exaggerated the speed of the natural processes of repair. " 606 " has, no doubt, a very definite effect upon the tissues apart from syphilis, but it cannot achieve the impossible. Some 12,000 cases have up to now been treated, with 12 deaths, a number of accidents which, occurring as they did in the experimental stage of the drug, may readily be reduced in the future. These cases, or at any rate the great proportion of them, are claimed to have been cured, that is, cured in the strict sense of the word.

In order to guard against any repetition of such disasters as followed the introduction of such potent remedies as tuberculin and atoxyl, Ehrlich determined, even in the face of criticism, to give the preparation only to individuals working in recognised laboratories, where his directions could be cautiously carried ont. Thus, in the space of a few months, by means of a lavish supply of material, the first epoch, as Ehrlich himself says, has been successfully passed. The results and method of application are for the most part known. There remains the question of permanenoy only.

The Principles Underlying Chemotherapeutics and "606."

Dioxydiamidoarsenobenzol is a substitution product of atoxyl, the great feature of this new preparation of arsenic lying in the fact that the quantity required as a therapeutic dose is only a small fraction of that which can be given without toxic results following. This preparation, like several of the other substitution products of atoxyl, is the outcome of elaborate researches on the part of Professor Ehrlich and his co-worker Dr. Bertbeim. The preparation of such products became comparatively simple after they had shown that atoxyl was sodium paramidophenylarsenic acid, and not sodium metaarsenious acid anilid, or, in other words, that the amido radicle was not bound up with the arsenic directly. In this way, mainly by substitution and reduction, most of the new compounds, such as acetylatoxyl, paramidophenylarsenoxyd, arsenophenylglycin, \&c., have been obtained. The following graphic formulæ give the steps, according to Ehrlich, by which " 606 " may be obtained

1 From the Bacteriological Laboratory, London Hospital. 2 The Lancet, Sept. 3rd, 1910, p. 713. 
from atoxyl. A-atoxyl, as stated above, is the sodium salt of para-amidophenylarsenic acid, of which a formula is shown in Fig. 1 :-
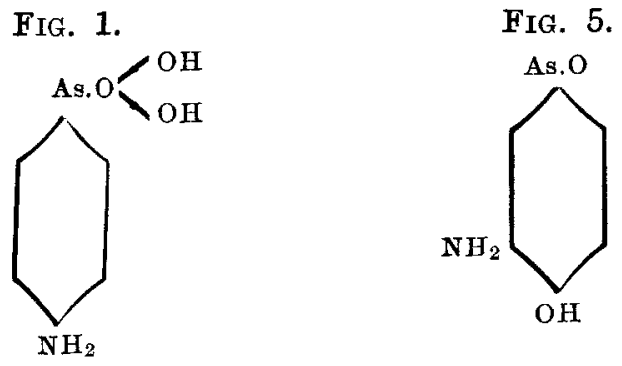

FIG. 2.

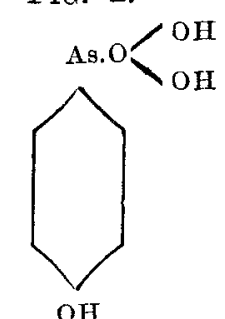

$\mathrm{OH}$

FIG. 3.<smiles>O=[W]1CC[C@H](O)[C@H](OO)C1</smiles>

FIG. 4.

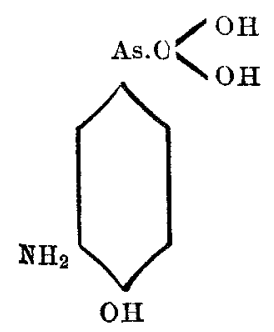

The amido radicle in Fig. 1 is replaced by a hydroxyl radicle by treatment with nitrous acid, which gives us paraoxyphenylarsenic acid (Fig. 2). By treating this new compound 2 with nitric acid, the nitro radicle is introduced into the meta position (Fig. 3). Reduction of compound 3 produces metaamidoparaoxyphenylarsenic acid (Fig. 4). Further reductions give us Fig. 5 and then Fig. 6-dioxy. diamidoarsenobenzol, or "606." This compound being quite insoluble, a hydrochloride was prepared which is the yellow salt supplied by Professor Ehrlich. This on nentralisation with sodium hydrate gives us the sodium salt (Fig. 7). For commercial purposes " 606 " is prepared in a much simpler manner from arsenobenzol by the substitution of amido and hydroxyl radicles into the nucleus. It would appear that the activity of these substances depends upon the exact relationship of one radicle to another. Ehrlich considers that when there are two or more substitution molecules in the benzene ring one of which is capable $\left(\mathrm{OH}\right.$, or $\mathrm{NH}_{2}$ ) of forming further combinations, the third radicle must be in the ortho position to the radicle capable of uniting with other com. pounds. In " 606 " the $\mathrm{NH}_{2}$ radicle is in the ortho position to the $\mathrm{OH}$ radicle.

In the above compounds the amido radicle is perhaps of the greatest importance, for, as already stated, it was only after the discovery that in atoxyl the amido group was not bound up with the arsenic that these new and more efficient remedies were discovered. The fact that the arsenic is trivalent in " 606 " instead of being pentavalent as in the case of atoxyl is also believed to be an important factor in the efficacy of the remedy. Whether the amido radicle acts as the anchoring agent or as an auxiliary to the toxic influence of arsenic on the parasites is not quite clear, but it seems that the transposition of the amido radicle into the third position of the benzene nucleus has brought about a marked diminution in the organotropic properties of the medicament, without reducing in any way its parasitotropic qualities. In other words, these workers aimed at obtaining a remedy which approached as nearly as possible the most perfect therapy known-namely, serum therapy.

Chemotherapy has as yet been directed principally against micro-organisms of a protozoal origin, which the human body does not seem capable of destroying unaided. Recent researches have shown that Ehrlich's "Therapia sterilisans magna" is the most efficient method of dealing with such conditions. The introduction of this method of treatment was necessitated by his discovery that many organisms, chiefly of protozoal origin, had the power of becoming immune or resistant to injurious substances met with in the animal body. This fact explains the recurrence of trypanosomes and spirochretes in the blood of men and animals after apparent cures by a medicament. Relapses in infectious diseases can now be more intelligently explained by means of these facts.

The chronicity of protozoal and spirochæte infections is without doubt due to the same cause, as the parasites are able to protect themselves against each fresh output of antibody by the animal organism, till at last a condition of equilibrium is established between the two. In this state the chronic manifestations of the disease make their appearance. Nature for some reason does not seem able to upset this equilibrium until outside assistance has been given. In chemotherapy we have a means by which assistance can be given to the natural protective functions.

The manner in which a chemical compound such as dioxydiamidoarsenobenzol effects a destruction of the parasites in the organism is not a simple process. We know from the researches of Koch that the action is not of an antiseptic nature, as the ordinary antiseptics are as injurious to the host's tissues as to the parasites. A chemotherapeutic remedy must, therefore, possess a selective affinity for the parasite's protoplasm, in contra-distinction to that of the tissue cells. In order to explain this selective action Ehrlich has modified his side-chain theory of immunity to make it applicable to the study of chemotherapeutics. He terms the receptors in this case "chemoreceptors," the presence of such receptors in the protoplasm of the parasite being necessary before the remedy can fix itself thereto. When once the chemoreceptors of the parasite have been filled it is either so injured that it dies immediately or becomes an easy prey to the normal protective mechanism of the body. This hypothesis, then, of Ehrlich is really founded on the affinity of certain dye stuffs for certain tissues of the body. It is unlikely, however, that many chemotherapeutic remedies are sufficiently powerful to cause by themselves in every instance an immediate and complete sterilisation of the infected animal. Probably they destroy the majority of the parasites, and these destroyed parasites, being now in the condition of a soluble antigen, are the means by which a great increase of antibody is produced. The increased quantity of immune body may be sufficient to kill off any remaining parasites either by direct lysis or through phagocytosis. This probably occurs in the case of "606," as experiments on animals have shown. that an elaboration of antibodies follows rapidly on the introduction of " 606 " into the infected organism, no matter at what stage of the disease the injection is made. In other cases the remedy has no direct lethal effect on the parasites, but nevertheless it injures them in such a way that certain of their vital functions are inhibited, as, for instance, reproduction, so that in a short time the parasites die out. It is also likely that some of these compounds so change the physico-chemical condition of the parasites' surroundings that the host's tissues and fluids are no longer suitable media for their continued existence.

Chemotherapeutic substances are usually grouped according to their manner of acting on the parasiles as follows:1. No action on certain parasites either in vivo or in vitro. In such cases either suitable chemoreceptors are absent from the protoplasm of the parasite or the receptors of the tissue cells of the host's organs have a greater affinity for the remedy than have the micro-organisms. In the latter condition the organotropic properties of the medicament are in excess of its parasitotropic qualities. 2. No action in vitro; marked action in vivo. A result which may be brought about in one of three ways: (a) by the remedy undergoing some change, in the body of the animals, by which it is converted into a parasiticidal substance; $(b)$ by causing an 
inhibition of some vital tunction of the parasite such as reproduction; or (c) by stimulating the natural mechanism by which the host rids itself of micro-organisms in con junction with either of the two previous effects. 3. Action in vivo and action in vitro.

As previously pointed out, the difficulty of treating protozoal infections is due to the power which the parasites possess of causing relapses, these relapses or recurrences being due to the facility with which these parasites become immune or resistant to various toxic bodies, whether of an inorganic or organic origin. Ehrlich attributes the resistance of these "fast" strains to a shedding of their chemoreceptors or to a diminution or complete loss of all avidity on the part of these receptors. Whatever this acquired resistance may be due to, the remarkable fact has been demonstrated that this property is persistent in the strain for generations afterwards. Thus we are able to realise the intention of Ehrlich's therapia sterilisans magna, since by destroying the parasites at one blow, so to speak, the possibility of a resistant strain springing into existence is prevented. In many of the cases where a therapua sterniisans magna is employed an artificial crisis is produced. This crisis apparently resembles in every way that which occurs naturally at a later period of the infection.

Precautions to be Foliowed Before the Exhibition of "G06."

In order to diminish the occurrence of any injurious effects Ehrlich advises that before an injection of " 606 " be given a careful examination of the patient be made. Special attention should be paid to the condition of such important organs as the heart, liver, and kidneys. If changes are found which are likely to interfere considerably with the functional activity of these organs it is advisable not to give "606." In the same way gross alterations in the nervous system are contra-indications. If, however, these lesions are most likely of syphilitic origin the danger accruing from the use of " 606 " is greatly lessened, though the more recent observations have shown that the use of " 606 " in those cases where the nervous system has been considerably involved even by the syphilitic virus is fraught with considerable danger to the patient.

Ehrlich also considers that it is necessary to ascertain previous to the injection whether the patient has an increased susceptibility to arsenic or not. In order to ascertain whether this condition of "allergie" exists, a test similar in detail to von Pirquet's tuberculin reaction is made except that a solution of arsenic is used instead of tuberculin. If the patient has any hypersusceptibility to arsenic an inflammatory reaction is said to occur at the site of the puncture. Recent results have indicated, however, that such a precaution is wholly unnecessary.

\section{Dosage.}

In the earlier cases Ehrlich advised a dose of 0.3 gramme ; this quantity, however, was found to be insufficient. The amount usually given now for an average adult is 0.6 gramme; more may be given without ill effects, but at present larger single doses appear to be unnecessary.

\section{Technique of Injection.}

In our earlier cases the remedy was given by intramuscular injection into the buttocks according to Alt's formula. More recently we have also usea a neutral suspension of the remedy subcutaneously, as advised by Michaelis and Wechselmann. We have had no experience of intravenous injections and think there is no necessity for the employment of such means, though Schreiber and others have described improved effects. The least painful of these methods is, of course, the intravenous injection. The pain caused by the neutral suspension is slight in comparison with that following the injection of the remedy as advised by Alt, but patients of apparently equal fortitude appear to experience very varying discomfort.

The site of inoculation is also worthy of consideration; our observations tend to show that subcutaneous injections in the scapular region are rather less painful and inconvenient than intramuscular injections in the gluteal region. But the fact that in some cases there is apt to be a more severe local reaction after subcutaneous injections, or even the formation of a sterile abscess, rather tends to counterbalance the advantages of this method. Local irritation, however, appears to be considerably diminished if care is taken to prevent any of the injection remaining in the puncture or its neighbourhood.
Alt's method of giving dioxydiamidoarsenobenzol consists of injecting a solution of " 606 " in caustic soda. The preparation given out by Professor Ehrlich in sealed and exhausted glass bulbs is a hydrochloride of dioxydiamidoarsenobenzol, and this acid salt must be neutralised before use, On the addition of sodium hydrate a precipitate falls which consists of the sodium salt of this hydrochloride of "606." This precipitate is soluble only in excess of sodium hydrate. The pain which follows an injection of this alkaline solution is to some extent caused by the excess of alkali in it. Alt advises that the required quantity of the remedy should be placed in a sterile test-tube and dissolved in 0.5 to 1.0 c.c. of the purest methyl alcohol (pro analysi). To this solution 10 c.c. of sterile saline solution are added, and then the whole is neutralised with a normal solution of sodium hydrate; a few more drops of sodium hydrate are added til the precipitate which has been formed is all dissolved 20 per cent. acetic acid is now slowly added to remove excessive alkalinity until the solution is slightly opaque, and after it has been made up to 20 c.c. it is ready for injection, on the addition of some anæsthetic such as eucaine. Owing to the readiness with which the compound decomposes it is essential that it be nsed immediately or shortly after it bas been prepared. We, however, find it better to dissolve the required amount of " 606 " in much less liquid than is advised by Alt. If a little care be exercised in making up the remedy it will be found to go completely into solution in as small a volume of fluid as 6 or 10 c.c. By this means the whole amount of "606" can be given in one injection, therebs saving the patient a lot of unnecessary pain. The higher concentration of salts in the solution does not cause an increase of pain. The injection ought to be made high up in the gluteal region, in a spot situated about the junction of the upper and middle third of a line drawn from the anterior superior iliac spine backwards to the top of the gluteal fissure.

The neutral suspension of Michaelis must also be made up just previous to use. The "606" is dissolved in 0.5 or 1 c.c. of methyl alcohol as before, and then about 10 c.c. of sterile saline are added. This acid solution is made neutral to litmus or phenolphthalein by the addition of a solution of normal sodium hydrate. If the neutral point is exceeded a small amount of acetic acid may be added. The dioxydiamidoarsenobenzol is present as a bulky yellow precipitate. The mixture is then centrifuged for a short time, and the clear supernatant fluid poured off. The precipitate is now emulsified in 100 c.c. of saline and injected subcutaneously or intramuscularly. In the above manipulations the strictest asepsis must be observed as the preparation cannot be sterilised.

If it is wished to give an intravenous injection the remedy is made up according to Alt's method, but the volume of liquid should be made up to 200 c.c., so that a clear solution is obtained which is also much less alkaline.

All our injections have been made by means of a "record" syringe with an ordinary steel needle, which, however, should be heavily plated. The neutral suspension necessitates use of a needle with a wide bore.

The patients were all kept in bed for a few days after the injection in case of any complication arising and for better observation. Their sera were examined for the Wassermann reaction before the injection was given, and at intervals afterwards ; where possible a search was also made for spirochætes before and after the injection.

In the following short abstract we have thought it neces. sary to present all the cases of syphilis treated by us, and we have been careful not to over-estimate the beneficial influence of the drug. With two exceptions, these patients have been admitted into the London Hospital by Dr. J. H. Sequeira, and have been continuously observed by him both while in his beds and afterwards in his dermatological clinic. The cases, therefore, have been controlled by a very wide clinical experience.

CASE 1.-A female, aged 23 years, had a large chancre in the middle of the upper lip in process of healing with ulceration of its inne aspect. There were a general desquamating papular rash, an ulcerated throat, and enlargement of glands. The sore had been present for about four months and the rash for one montb. On Julv 19th, 1910, the patient was inoculated in both glutæi with 03 gramme of " 606 " in solution. Three days later the chancre had healed, the recent spot had disappeared, while the older ones were fainter. After six days all spots had gone, leaving a pigmentation only. On the eighth day no glands were palpable, and on the tenth slight pigmentation of the ras only was observed. After three months the patient was in perfect
health and had increased in weight $8 \mathrm{lb}$. No general reaction was 
observed in this case. The local pain did not appear to us to be severe. On Oct. 20 th the Wassermann reaction became slightly positive. On Nov. 3rd the patient returned with slight malaise, some four or five
spots, two mucous patches, and slight sore throat. No spirochætes Fere found in the lesions. Wassermann reaction positive. On Nov. 15th she was given 0.6 gramme of " 606 " in solution in
gluteally, which produced a rapid disappearance of the symptoms.

CASE 2.-A male, aged 30 years, had a bard chancre 13 inches long on the lower lip. The right submental and cervical glands were enlarged, but there was no other sign of syphilis. The patient was said to have
been bitten on the lip in a fight. The sore had been present for three been bitten on the lip in a fight. The sore had been present for three 0.3 gramme of " 606 " in solution, and in two days the chancre was softer and the glands were smaller. Six days after the injection the smaller. On the ninth day the unhealed area was three-quarters of an
inch long. In five weeks the patient returned with the chancre no smaller and a very marked macular rash on the forearms. He was, therefore, again inoculated on Sept. 22nd with 0.6 gramme of " 606 ." The chancre rapidly healed, leaving a slight induration; the rash faded. the disease. After the first inoculation the pain was very severe in the disease. After the first inoculation the pain was very severe in
both glutæi and in the knees and the calves, and it lasted for two both glutæi and in the knees and the calves, and it lasted for two
days. There was, however, no general reaction; the second inoculation was comparatively painless. In this case the temperature rose to $99.2^{\circ} \mathrm{F}$.

CASE 3. - The patient, aged 29 vears, a male, was melancholic. He had a bad septic throat and suffered from earache. He had also a macular rash which was fading from the trunk and was marked on the buttocks. He had bad a sore on the penis in October, 1909, without any rash. This latter did not appear until June, 1910, at which time also the sore throat and earache started. On August 33 th his Wasser-
mann reaction was completely positive, but on the 26 th it was only partially so. At this latter date he was injected with 0.4 gramme of

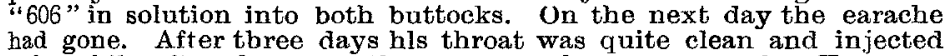
had gone. After tbree days hls throat was quite clean and injected
only, while after five days there was no longer any rash. However, after seven weeks, the throat was no better and the earache started on the other side. At the same time his Wassermann reaction again became completely positive and further treatment is intended. The pain at the time of

general disturbance.
CASE 4.-The patient, a female aged 19 years, had a small chancre in the middle of the upper lip and enlargement of glands. The chancre bad been present for 10 weeks. On Sept. 9 th, 1910 , she was inoculated with 0.4 gramme of " 606 " in solution into both glutæi. In seven days the chancre was almost healed, and in 19 days it was completely healed. She has not been observed again The pain was moderate and lasted for
24 hours. The highest temperature was $99 \cdot 22^{\circ} \mathrm{F}$., and the quickest pulse-rate 95 .

CASE 5.-A male, aged 34 years. This man had a large suppurating sore on the left cheek with very marked general rash and glandular present for five weeks and the rash for 17 days. On Sept. 22nd, 1910, he was inoculated with 0.6 gramme of " 606 " in solution into both glutæi. In seven days the rash had nearly gone and there was very healed the former the sore. After two weeks the sore was quite healed; the former rash was marked by a pigmentation only and the
glands were still enlarged. He had gained 8 lb. in weight. After five weeks there were no signs of the disease. Following inoculation the pain in the small of the back was very severe for five days. For the same time the pulse ranged from 90 to 96 . There was no other
the reaction.

CASE 6.-A female, aged 26 years, had a general macular rash. Her face was very badly affected and was desquamating. present for six weeks. She was inoculated in the glutri on Sept. 29th, present for six weeks. She was inoculated in the glutwi on Sept. 29 th, was a marked Herxheimer reaction followed by a rapid diminution of was a marked Herxheimer reaction followed by a rapid diminution of the fourteenth day there was still a slight mottling and the glands were enlarged. Five weeks after the inoculation the patient was quite well. The pain did not appear to be severe and there was no general

CASE 7.-A female. aged 26 years, with marked general papular and macular eruption. The throat was sore and the glands were enlarged. The rash had been present for about 10 days. She was inoculated on
Sept. 29th, 1910, in both glutæi with 0.5 gramme of " 606 " in solution. In one day the former very marked rash on the hands and face was only visible on close inspection. The rash faded until on the seventh day there was little left; the sore-throat also had gone. After four weeks
there was still a slight pigmentation in places. This patient did not complain of much pain and there was no general reaction.

CASE 8. -The patient was a male aged 26 years. He had a small

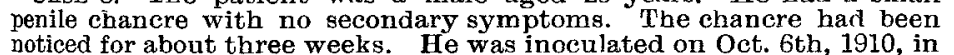
both scapular regions with 0.6 gramme of " 606 " in suspension. In one day the chancre was flatter and cleaner. On the fourth day it was clearly healing and on the fifteenth day had completely healed. No night of the inoculation the patient had a profuse sweat with a temperature of $101.4 \circ \mathrm{F}$., a pulse rate of 100 , and a respiration rate of 24 . The
urine was normal. After the first day there was no further disturbance.

CASE 9. - The patient, a male, had a widespread indurated ulceration lip. This lower lip, the chin, the left cheek, and half of the uppe years similar conditions had arisen on rarious parts of the past five usually had taken four months to heal with iodide of potassium. There negative. The patient was inoculated on Oct. 6th, 1910 , with 0.6 gramme of " 606 " in suspension in both scapular regions. In four days the ulceration was very much cleaner, but the inflammatory area was no epitbelial proliferation. After three weeks the healing was still pro gressing and in one month was nearly complete. A considerable tion. In this case also there was a profuse sweat during the first night with a temperature of $99 \cdot 4^{\circ} \mathrm{F}$. Otherwise there was no general

disturbance.
CAsE 10.- The patient, a male, aged 40 years, was under the:care of
Dr. Arthur Whitfield at King's College Hospital. He had a large Dr. Arthur Whitfield at King's College Hospital. He had a large left eyelid and a great part of the nose. There was \& tendency to left eyelid and a great part of the nose. There was a tendency to
ulceration at one place only. The man had been infected 23 years ulceration at one place only. The man had been infected 23 years
before and had had a gummatous relapse 10 years ago. Dr. Whitfield fefore and haw him in May, 1909, when he had a widespread condition of the left upper arm which had been diagnosed as psoriasis. This cleared up rapidly under mereurial inunctions and later pills. He discontinued treatment with the present result which has dated from the summer of
this year. On Oct. 10th, 1910, he was inoculated with 0.6 gramme of "606" in suspension in both scapular regions. In 24 hours the lesion was paler and in four days it was almost flat though heavily pigmented In ten days a large pustule occurred on the nose with an increase of redness. This healed in about four days. In three weeks the lesion was quite resolved, leaving some brown staining only. He increased 5 pounds in weight in the first week. The pain after inoculation was evere and there was a rise of temperature to $100^{\circ}$

CASE 11.-The patient, a male, aged 15 years, had congenital syphilis and a widespread inflammatory and ulcerative condition of the face nose, and upper lip which had provisionally been diagnosed as lupus. The nose was depressed and obstructed by discharge. Double otitis The hearing was very feeble on the right side and was absent on the left. There were interstitial keratitis and choroinitis on both sides. The patient was blind in the left eye, and on the right side there were very high myopia and dimness of vision. The condition had been
progressing for four years. On Oct. 10th, 1910, he was inoculated with progressing for four years. On Oct. 10th, 1910, he was inoculated with 0.1 gramme of " 606 " in suspension in the scapular region, and on the
12th with 0.2 gramme intc the buttock. On this day (two days after the first ivoculation) he spontaneously remarked that he could see better. On the third day the injection of the left eye and the opacity of the pupil were less. In five days there was very marked diminution in the size of the swollen lip. The inflammatory redness had gone from the face. The nasal discharge had ceased, permitting a cessation of the dressings. On the seventh day the patient could breathe freely through his nose. Ten days after the first inoculation he had a bad "cold," with foul aural discbarge and increased redness of the lip. On the 25 th he was again inoculated with 0.2 gramme of " 606 in the shoulder ondition. Both inoculations in the persistent improvement in his indurations but little pain. After the second inoculation the temperature rose to $99^{\circ} 4^{\circ}$

C $\triangle S E$ 12.-The pationt, a male, aged 22 years, was under the care of Dr. J. Sangster Greig at West Ham Union Infirmary. He had a phagedenic chancre on the side of the prepuce $1 \frac{1}{2}$ inches long, associated with ulceration of the glans penis. There was a general papular present for two months and the rash one month. On Oct. 10th, 1910, be was inoculated with 0.6 gramme of "606" in solution into both glutæi. A slight Herxheimer reaction followed. In six days the rash was gone, the chancre half healed, and the glands practically normal. he was quite cured, and had increased 10 pounds in weight. The local pain was not severe, and the temperature rose to $99^{\circ} 6^{\circ} \mathrm{F}$. only.

CASE 13.-The patient, a male, aged 25 years, had a healed chancre and a fading secondary rash all over, with much desquamation The rash was marked on the face, neck, bend of elbows, \&c. There were general glandular enlargement and gleet. The chancre appeared three or four months before and the rash six or eight weeks. On Oct. 12th, 1910 , he was inoculated with 0.6 gramme of " 606 " in suspension into
both shoulders. In three days the rash bad nearly gone from the both shoulders. In three days the rash bad nearly gone from the trunk and was fading from the face; in seven days the rash was hardly
visible, while in 16 days all signs of disease had disappeared. He had visible, while in 16 days all signs of disease
very little pain and a temperature of $99.5^{\circ} \mathrm{F}$.

CASE 14. - The patient, aged 28 years, was the mother of Case 15. There were no symptoms of syphilis. The Wassermann reaction was
negative. Her children are healthy, the last being born four and a half years ago. There was a history of syphilis, she having had a rash which started two years ago and lasted until the time of conception of Case 15. She was inceulated on Oet. 14th. 1910, with 0.5 gramme of Just after inoculation she developed a severe "cold," with a temperature of $101^{\circ} 6^{\circ} \mathrm{F}$. and malaise. This lasted three days.

CASE 15.-The patient was a male aged 4 weeks. He had pemphigus and a rash all over the body and nasal discharge. He had had six inunctions of mercury with benefit, but other spots were coming out. Dr. Sequeirs thought that the child might live. The condition started four days after birth The baby was not inoculated but was suckled by the mother. Three days after the mother's treat-
ment the rash and pemphigus had nearly gone. In ten days the baby was quite well and is now thriving. No ill-effects were observed in the

Case 16.-The patient was a male aged 2 weeks. There were-
severe general bullous pemphigus and diarrhoea. The child had shed severe general bullous pemphigus and diarrhoea. The child had shed nearly all his skin. Dr. Sequeira thought that the baby would die. "On Oct. 14th, 1910, he was inoculated with 0.02 gramme of " 606 " in
suspension into the glutæus muscle. In three days the rash and pemphigus had practically gone. In four days there were a few spots only and no diarrhoea. Up to the seventeenth day the baby had been thriving; on this day he was again inoculated with 0.06 gramme of "606" in the shoulder. Local redness and swelling followed the tirst inoculation and seven days after a very small slough separated from the
The second point of inoculation. There was no general disturb
inoculation also has been followed by no ill-effects.

Drsappearance of spirochetes. - The action of " 606 " on the Spirochæta pallida in the primary lesion is very rapid, as in Cases 2 and 8 . No spirochætæ could be found in the primary lesion 24 hours after the remedy had been given, though just previous to the injection they were present in large numbers. The greatest destruction of spirochæes apparently took place 5 to 12 hours after the injection. No doubt those actually in the system are attacked at an earlier period. 
Mercury, on the other hand, takes about three weeks to bring about this result. The above fact alone serves to stamp dioxydiamidoarsenobenzol as the greatest antisyphilitic remedy we possess.

Leuoocytosis. - In none of the above cases have we observed any such marked degree of leucocytosis as has been described by different writers.

Effect of "606" on the Wassermann Reation.

\begin{tabular}{|c|c|c|c|c|c|c|c|c|c|c|c|c|}
\hline \multirow{2}{*}{$\begin{array}{l}\text { Number of } \\
\text { case and } \\
\text { stage } \\
\text { of disease. }\end{array}$} & \multirow{2}{*}{$\begin{array}{l}\dot{0} \\
\dot{8} \\
\dot{0}\end{array}$} & \multirow{2}{*}{$\begin{array}{l}\dot{0} \\
0 \\
0 \\
0\end{array}$} & \multicolumn{10}{|c|}{ Weeks after- } \\
\hline & & & 2 & 3 & 4 & 5 & 6 & 7 & 8 & 9 & 10 & 12 \\
\hline $\begin{array}{l}\text { Case 1. } \\
\text { I. and II. }\end{array}$ & 0.3 & $\mathrm{C}$ & C & MO & - & - & - & - & 0 & - & - & 0 \\
\hline $\begin{array}{l}\text { Case } 2 . \\
\text { I. }\end{array}$ & $\left.\begin{array}{ll}0 & 3 \\
0 & 6\end{array}\right\}$ & C & M & o & - & - & $\mathrm{O}$ & $\mathrm{O}$ & - & - & O & - \\
\hline $\begin{array}{l}\text { Case 3: } \\
\text { II. }\end{array}$ & 0.4 & os & - & - & - & - & - & $\mathbf{S}$ & - & $\mathbf{C}$ & - & - \\
\hline $\begin{array}{c}\text { Case } 4 . \\
\text { I. }\end{array}$ & 0.4 & $\mathbf{C}$ & - & $\mathbf{S}$ & - & - & - & - & - & - & - & - \\
\hline $\begin{array}{l}\text { Case } 5 \text {. } \\
\text { I. and II. }\end{array}$ & 0.6 & C & $\mathbf{C}$ & $\mathbf{C}$ & - & $\mathbf{C}$ & - & - & - & $\mathbf{M}$ & - & - \\
\hline $\begin{array}{l}\text { Case } 6 . \\
\text { II. }\end{array}$ & 0.5 & C & C & $\mathbf{C}$ & $\mathbf{C}$ & C & - & $\mathbf{M}$ & - & $\mathrm{O}$ & - & - \\
\hline $\begin{array}{c}\text { Case } 7 . \\
\text { II. }\end{array}$ & 0.5 & $\mathbf{C}$ & C & - & $\mathrm{C}$ & - & - & - & $\mathbf{C}$ & 一 & - & - \\
\hline $\begin{array}{c}\text { Case } 8 . \\
\text { I. }\end{array}$ & 0.6 & $\mathbf{C}$ & $\mathbf{M}$ & 0 & $\mathrm{O}$ & $\mathrm{O}$ & - & - & - & - & - & - \\
\hline $\begin{array}{c}\text { Case } 9 . \\
\text { III. }\end{array}$ & $0 \cdot 3$ & 0 & 0 & $\mathrm{O}$ & - & 0 & $\mathrm{O}$ & 0 & - & - & - & - \\
\hline $\begin{array}{l}\text { Case } 10 . \\
\text { III. }\end{array}$ & 0.6 & $\mathrm{C}$ & $\mathbf{C}$ & C & - & - & $\mathrm{C}$ & - & - & - & - & - \\
\hline $\begin{array}{c}\text { Case } 11 . \\
\text { Congenital. }\end{array}$ & $\left.\begin{array}{l}0.1 \\
02 \\
0.2\end{array}\right\}$ & C & C & - & $\mathrm{C}$ & $\mathbf{C}$ & - & $\mathbf{C}$ & $\mathbf{C}$ & - & - & - \\
\hline $\begin{array}{l}\text { Case } 12 . \\
\text { I. and II. }\end{array}$ & 0.6 & $\mathrm{C}$ & $\mathbf{M}$ & $\mathbf{S}$ & - & - & 0 & 0 & - & - & - & - \\
\hline $\begin{array}{l}\text { Case } 13 . \\
\text { II. }\end{array}$ & 0.6 & C & $\mathrm{C}$ & - & $\mathrm{C}$ & - & C & $\mathbf{C}$ & - & - & - & - \\
\hline $\begin{array}{l}\text { Case } 14 . \\
\text { Latent. }\end{array}$ & 0.5 & 0 & 0 & - & 0 & 0 & - & - & - & - & - & - \\
\hline $\begin{array}{c}\text { Case } 16 . \\
\text { Congenital. }\end{array}$ & $\left\{\begin{array}{l}0.02 \\
0.06\end{array}\right\}$ & - & - & - & - & - & - & - & - & - & - & - \\
\hline
\end{tabular}

$\mathrm{C}=$ Completely positive reaction. $\mathrm{M}=$ Medium positive reaction. $\mathrm{S}=$ Slightly positive reaction. $\mathrm{O}=$ Negative reaction.

We do not suppose that " 606 " can directly influence the Wassermann reaction, but by its destruction of the spirochætæ it removes the cause. At any rate, the rapidity with which in some cases the patient's serum loses the power of giving a positive Wassermann reaction is one of the greatest arguments in favour of Ehrlich's new specific. In our own cases, as can be seen in the above table, the earliest period at which the reaction has disappeared after an injection is three weeks (Cases 1, 2, and 8). It will be seen that two of these cases were in the first stage of the disease. The reaction disappears much more slowly in cases of secondary syphilis, and, in fact, has already persisted in some of our cases for seven weeks. These results are not surprising, as in primary syphilis the Wassermann reaction is usually a weak one, though completely positive. There is in these cases little or no excess of reacting substances in the serum. In secondary syphilis, however, there is a much larger quantity of the Wassermann-producing substances in the serum, and it is only logical to expect that they will take a longer time to disappear. We are convinced that the information supplied by the Wassermann test is an essential indicator of the patient's progress. If the reaction fails to become negative after an interval of several weeks, it is to be suspected that the patient is not doing so well as he should, and in all probability will have a relapse, as was the case with patient No. 3.

Effects on Lesions.

In the case of primary lesions, genital or extragenital, the process of repair is very rapid. In contradistinction to the five or six weeks required for the disappearance of a chancre under ordinary treatment, only from 10 to 14 days were required for complete healing. Secondary lesions, as a rule, show an improvement within 24 hours of an injection of "606." In the case of the secondary eruption, however, the pigment appears to persist for a long time; this persistence of the pigment is no doubt only relative, as after an injection of "606" the absorption of the inflammatory lesion is no longer a gradual process as when mercury is used, but an immediate one. In tertiary lesions the effects are much more varied. Some disappear as if under a magic influence; others, again, show little or no alteration for some days after the injection. In congenital syphilis even of the worst types the rashes disappear in two or three days. Lesions of a more chronic nature, such as interstitial keratitis, resolve very much more slowly.

\section{Question of Temperature Response to " $606 . "$}

The alteration in temperature after an injection of " 606 " in cases of primary and secondary syphilis is comparable to what occurs in certain acute infections which terminate by crisis. In other words "606," owing to the rapidity with which it sterilises the human organism of spirochætes, produces a cure in these stages by a definite crisis. The patient's temperature rises as a rule one or two degrees $\left(100^{\circ}\right.$ or $101^{\circ} \mathrm{F}$.) within 12 hours, after which it falls almost as suddenly as it rose. The patient at the same time experiences a profuse sweat. If the temperature is high at the time of inoculation it usually falls to normal about 24 hours later. This temperature response is not observed in the majority of patients suffering from latent or tertiary syphilis. No doubt the flooding of the system with an excess of soluble spirochæte products is the actual cause of these phenomena.

\section{Relapses.}

In Cases 2 and $3^{1}$ it will be noticed that relapses occurred, but not relapses in the sense of a clinical recurrence after a clinical cure. Neither of these patients had cleared up after one inoculation, which, it must be observed, was in each instance small. These accidents, to a large extent, must depend upon the size and spacing of the doses. The question arises as to whether one dose on the average is sufficient to produce complete sterilisation of the body, however large it may be. We take it that " 606 " is intended to have a lethal influence on spirochætes, but that all the spirochætes in the body are not destroyed by this influence. The residuum, great or small, is overcome by the antibodies to "endotoxins" liberated from those spirochrtes destroyed by the " 606." Thus if there are few spirochætes in the body, there will be a small output of antibody, perhaps insuficient to finish the cure or at least liable to delay it. Such a state may be present when the Wassermann reaction is negative or feeble. This is held to imply the presence of a small quantity of the virus in the body. It is also known that arsenic circulates in the system for a very short time after injection: it is very rapidly "fixed" by the tissues, especially the kidney. What, then, is to be expected in cases such as Nos. 3 and 9 with feeble and nega tive Wassermann reactions? The arsenic which is absorbed destroys, indeed, some spirochætes, but most is "fixed" by the tissues and lost. The production of "endotoxin" and subsequent antibody is small. Sterilisation in the one case was incomplete ; in the other recovery was at least slow, and will probably also be incomplete. In cases of this sort, therefore, as also in cases of primary syphilis, if not in syphilis of any variety, we think that more than one dose will be found to be more certain in action. Ehrlich recom. mends an initial large dose given intravenously, or if there is thought to be objection to this, intramuscularly, in solution. This ensures a rapid absorption and a sharp iotus immunisotorius, leading to a maximum destruction of spirochetes and production of antibody. Then, since the first injection will be rapidly wasted, on the second or third day, a second dose in suspension should be given to act as a "depôt" over a considerable time. All our recent cases have been treated on this principle. The patient is first given an injection of 0.5 to 0.6 gramme " 606 " in alkaline solution intramuscularly in the glateal region, the volume of liquid injected not being more than 10 c.c. Three days later he is given 0.4 gramme " 606 " neutral suspension intramuscularly in the opposite side.

The employment of " 606 " will probably assist in the elucidation of several points of interest in the immunity to syphilis. Among these are the changes which occur in the serum components of patients who have been treated with "606." That the Wassermann reaction should rapidly become

1 Since this paper went to press Case $I(q . v$.$) also relapsed, after an$ apparent cure lasting nearly four months. 
negative is not to be wondered at in view of the potency of the drug. We provisionally consider this reaction to be due to the presence of abnormal compounds in the blood, such compounds being the direct result of a destructive action by the living syphilitic virus on the tissues. If the virus is destroyed these compounds will no longer be formed, and those already present will be excreted in a few weeks or less according to the quantity originally present. The antibody which is formed by the presence of "endotoxins" is presumably a specific antibody and quite distinct from the Wassermann body, which is thought to be a direct degeneration product. If the latter were an antibody it could not be diminished by specific treatment. This has been demonstrated in experimental trypanosomiasis, where both specific antibody to the trypanosome and the Wassermann body are capable of being separately demonstrated.

Some writers have stated that a negative Wassermann reaction may become positive after inoculation. They assume that the soluble products, "endotoxins" of the spirochætes, are capable of bringing about that tissue degeneration which results in the Wassermann reaction. In the case of a negative reaction such products would be too few to detect, but as a result of inoculation a maximum output of " endotoxin "from the destroyed organisms suffices to produce the necessary tissue degeneration and a positive reaction. In three of our cases in which the reaction was negative or slight before inoculation no increase was observed. Any change has always been in the opposite direction. Many recent writers, moreover, have also failed to observe any such change, and as we are at present of opinion that in acute syphilis the Wassermann reaction is due to the active intervention of living spirochætes we are not surprised that these occurrences are rare.

In the literature there are already on record a few cases where the injection of " 606 " into the mother of a congenitally syphilitic baby resulted in a rapid and complete cure of that baby through the agency of the mother's milk. Such cases are explicable in two ways: first, that the injection of the mother with a positive Wassermann reaction by destroying a number of spirochætes produces in her a large amount of antibody, and that this antibody secreted in the milk brings about the recovery of the child; and secondly, that there is a direct transference of " 606 " by the milk. Ehrlich favours the former view, since in the cases published it was stated that no arsenic was found in the milk, or in a guantity insufficient to explain the therapeutic result. If this be the case it is difficult to explain our case No. 14. This woman had a negative reaction but a recent history of syphilis. In these circumstances she could not have produced sufficient antibodies as the result of a destruction of spirochætes. It is therefore possible that the " 606 ," merely by stimulation of the cells which previously had produced syphilitic antibody, caused a sufficient amount of these bodies to appear in the milk. It is, however, also possible that on the application of more refined methods arsenic may be demonstrable in the milk in larger quantities, and may take a more direct part in she cure than has been supposed.

This stimulating property of " 606 " may account for the great rapidity with which these antibodies are elaborated. The onset appears to be very much sooner than is the case in other immunising processes and cannot be altogether due to the large amount of antigen in the circulation as a result of the inoculation. That " 606 " has a stimulating effect on many metabolic processes can hardly be doubted. The subjective sensations of the patients are greatly improved, and where weight has been lost it is rapidly regained; for jnstance, Case 2 gained 7 pounds in 10 days, while Case 12 gained 10 pounds in 18 days. Further, inflammatory conditions subside, and a case of myelogenons leukæmia with 240,000 white cells per c. mm. before inoculation by us, one week afterwards had only 120,000. Such conditions as dropsy, œdema, and jaundice in one moribund non-syphilitic individual disappeared after inoculation, even though the cansative malignant disease killed the patient in a few days.

Certain phenomena noticed from time to time while using " 606 " in syphilitic cases can only be explained on the assumption of endotoxins liberated from the spirochæotæ. It has been shown that very young congenitally syphilitic infants are unsuitable for treatment except with very small doses, and the fatal results are explained by the very large quantity of endotoxins which must be produced from the innumerable spirochætes present in such cases. Again, we have observed the Herxheimer reaction in two cases. This reaction appears to be considered to be due to an insufficient dosage. It is suggested that the spirochres are not suff. ciently rapidly destroyed, that they have time to react to the noxious influence of " 606 " with an increased production of poisons. In our cases, however, the dose was not particularly small. We are at present inclined to look upon this phenomenon as being of the nature of an anaphylactic manifestation in an individual particularly sensitive to the syphilitic "endotoxins": a phenomenon comparable to those following the introduction of tuberculin or any other antigen into an already sensitised subject. These reactions have been particularly mentioned by Ehrlich as a cause of dangerous symptoms or death in the case of general paralysis and similar conditions. If in such a case of nervous degeneration a reaction occurs in an essential nerve, such as the vagus, the exitus lethalis will probably follow, and such an event, if these cases be operated upon, must be guarded against by the exhibition of very small doses.

The importance of " 606 " as a destroyer of spirochætes cannot be over-estimated, even apart from the beneficial effect upon the patient. In those cases in which spirochæes were demonstrable in very large numbers before inoculation, none were found in less than 24 hours, even after prolonged search. This fact has already been fully established. The importance of the observation lies in the probability that cases of syphilis can be rendered practically non-infective in a day or two. If this be true, Fhrlich will have swept away the scourge of 2000 years and given into the hands of any State, which will avail itself of it, a weapon for the forcible suppression of syphilis.

New Chemical Laboratories at University COLLEGE, LONDON. - On two previous occasions we have called attention to an appeal for $£ 70,000$ for the purpose of providing University College, London, with new chemical laboratories. We have now received a letter from Prince Arthur of Connaught, President of the appeal committee, stating that it is a matter of particular urgency that the sum of $£ 25,000$ should be raised before Christmas Day in order that the Senate of the University may exercise the option to purchase the Gower-place site. Towards this sum over $£ 10,000$ have now been raised. Donations sent to $\mathrm{His}$ Royal Highness, addressed to University College, London, will be acknowledged by him.

Food Congress. - The Deuxième Congrès de l'Alimentation will take place in Liége from Oct. 1st to 4th, 1911. This Congress has been organised in order to continue the work, as far as Belgium is concerned, of the Congress which was held at Paris in 1909 organised by the Société de la Croix Blanche de Genève and the Food and Hygiene Con. gress which was recently held at Brussels, organised by the Belgian Government. Foreign specialists are invited to take part-viz., physiologists, chemists, bacteriologists, hygienists, jurists, producers, merchants, \&c., in order that they may examine the whole question of food and discuss the measures to be taken to reconcile the requirements of hygiene and public health with commercial interests. The labours of the Congress will chiefly relate to the following food products-viz., milk, cheese, meats, poultry, fish, eggs, pickles, fats, bakery products, pastry, confectionery, chocolate, preserved vegetables, fruits, mushrooms, sugars, syrups, glucose, jams, tinned provisions, spices and condiments, waters, lemonades, ice, beers, wines, ciders, alcoholic drinks, vinegars, liqueurs, fruit juices, syrups, \&c. The president of the congress is Professor M. A. Jorissen, of the University of Liége, and an official of the Permanent Belgian Com mission of Human Alimentation. The vice-presidents are : M. Julien Delaite, M. de Molinari, M. J. Rarmond, M. L. Rutten, M. E. Sohier-Beaujean, and M. J. Van Zuylen. The secretary-general is Dr. F. Schoofs, secretary-general of the Permanent Belgian Commission of Human Alimentation. The treasurer is M. E. Halleux, barrister and secretary of the Union of Purveyors. All communications should be addressed to the secretary at Rue des Guillemins, 27, Liéye, Belgium. The subscription is fixed at 10 francs. The title of "Membres donateurs" will be given to those who subscribe at least 50 francs, and the title of "Membres protecteurs" to those who subscribe at least 200 francs. The family of regular members may become membres associés at 5 francs per person and will be invited to the fêtes. 